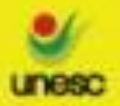

\title{
AS PROFESSORAS DAS SÉRIES INICIAIS NA REDE MUNICIPAL DE \\ MARACAJÁ E O ENSINO DA HISTÓRIA E CULTURA INDÍGENA
}

\section{THE TEACHERS OF THE INITIAL SERIES IN THE MUNICIPAL NETWORK OF MARACAJÁ AND THE TEACHING OF HISTORY AND INDIGENOUS CULTURE}

\author{
Márcia Sorato Rocha ${ }^{1}$ \\ Lucy Cristina Ostetto ${ }^{2}$
}

\begin{abstract}
RESUMO: Este artigo objetiva refletir sobre como acontece à abordagem da Lei 11.645/08 sobre o ensino da história e da cultura indígena na rede municipal de ensino de Maracajá, a partir da análise das práticas das professoras nos anos iniciais. Dentre os objetivos específicos deste trabalho, buscou-se constatar qual o conhecimento que as professoras possuem sobre a Lei, além de verificar se há formação de professores sobre o tema e refletir sobre as dificuldades e os desafios que estas professoras encontram para trabalhar esta temática na escola. Para tanto aplicamos um questionário com cinco professoras das três escolas municipais. Ao escrever nosso referencial, nos apoiamos em Alves (2015); Borges (2010); Freitas (2010); Funari e Piñón (2011); Proposta Curricular Nacional (1997, 1998 e 2001); Silva e Porto (2012); Zucchi (2012). Após a análise de dados concluímos que os objetivos foram alcançados, pois analisamos como acontece o ensino desta temática, além de constatar se as professoras recebem formação nesta área, quais os conhecimentos que possuem sobre a Lei 11645/08, quais as dificuldades e os desafios que encontram para levar o ensino desta temática para as escolas. Porém, os resultados não foram satisfatórios ao perceber que a maioria das professoras possuem conhecimentos estereotipados sobre este assunto e conhecem a Lei superficialmente.
\end{abstract}

PALAVRAS CHAVE: Ensino indígena. Lei 11645/08. Diversidade cultural. Prática das professoras.

ABSTRACT: This article objective to reflect on how happens the approach of Law $11645 / 08$, about the teaching of history and indigenous culture in the municipal education network of Maracajá, from the analysis of the practices of the teachers in the initial years. Among the specific objectives of this work, it was sought to understand the knowledge that the teachers have about the Law, in addition to verifying if there is teacher training on the subject and reflect on the difficulties and challenges that these teachers find to work on this theme in the classroom. We applied a questionnaire with five teachers from three municipal

\footnotetext{
${ }^{1}$ Acadêmica do curso de Pedagogia pela UNESC. Email: marciasoratorocha@ hotmail.com

${ }^{2}$ Professora da UNESC, doutoranda em História pela UFSC. Email: 1co@ unesc.net

Saberes Pedagógicos, Criciúma, v. 3, n³, Edição Especial 2019.- Curso de Pedagogia - UNESC
} 
schools. In writing our referential, divide ourselves into two moments, in the first we rely on Alves (2015); Borges (2010); Freitas (2010); Funari and Piñón (2011); National Curricular Proposal (1997, 1998, 2001); Silva and Porto (2012); Zucchi (2012). After analyzing the data we conclude that the objectives were achieved, because, we realize how the teaching of this subject happens, besides realizing if the teachers receive training in this area, what knowledge do they have about Law 11645/08, what difficulties and challenges they face in order to bring the teaching of this subject to schools, however the results were not satisfactory when realizing that the majority of the teachers have stereotyped knowledge on this subject, and know the Law superficially.

KEYWORDS: Indigenous teaching. Law 11645/08. Cultural diversity. Practice of the teachers.

\section{INTRODUÇÃO}

Ao pensar na história indígena, logo vem em nossa mente, aquela tradicional imagem do índio derrotado, aquele que perdeu suas terras para os colonizadores. Por muitas vezes, ainda predomina aquela imagem tão folclorizada no dia do índio, como uma data comemorativa, onde os alunos ganham rosto pintado e uma pena na cabeça, o qual se liga a uma imagem de corpos nus, com arco e flecha na mão, vivendo numa oca. E, no restante do ano letivo, não se ouve falar destes povos. Reina nas escolas um silêncio absoluto e uma completa invisibilidade. Visto que de acordo com Gallois

\footnotetext{
[...] para a maior parte dos brasileiros o "índio" continua sendo concebido como um "silvícola", que para ser reconhecido como portador de "cultura indígena" deve viver "no mato", morar em "ocas", "fazer pajelança", usar "cocar", etc. Essas ideias arraigadas a respeito do que seja "a cultura indígena" impedem que se atribua valor a inúmeros aspectos menos conhecidos, ou às adaptações criativas de saberes ancestrais que, localmente, cada grupo indígena produz, de maneira dinâmica e sempre articulada a seu ambiente, sua história e suas relações com outras comunidades culturais. (GALLOIS, 2006, p. 18).
}

Sabemos que a história e a cultura dos povos indígenas são, nesta perspectiva, simplificada e superficializada. Mas afinal, não existem índios no Brasil hoje, que resistiram e resistem a dizimação imposta pelos colonizadores? Suas terras foram demarcadas? Seus direitos são respeitados? Suas culturas, seus saberes e modo de vida são conhecidos e reverenciados como uma forma alternativa ao capitalismo desenfreado? Como vivem estes povos? Como se organizam? Quais suas pautas de luta? Como se reconhecem?

Saberes Pedagógicos, Criciúma, v. 3, n³ , Edição Especial 2019.- Curso de Pedagogia - UNESC 
Como uma forma de aproximar estas questões do cotidiano escolar, ou seja, questões que envolvem a história e a cultura dos povos indígenas, sobretudo pelo reconhecimento e valorização destes povos como formadores da sociedade brasileira, em março de 2008, foi aprovada a Lei 11.645/08, a qual alterou a Lei de Diretrizes e Bases, tornando o ensino da história e cultura indígena, africana e afro-brasileira obrigatório nas escolas de educação básica.

Esta Lei foi discutida no curso de Pedagogia, na disciplina de Processos Pedagógicos da História, no ano de 2017. Participei dessas aulas, e este tema me instigou muito, e então, senti vontade de levar esta temática para as escolas durante meu Trabalho de Conclusão de Curso, constatando assim, como está acontecendo à abordagem desta Lei nas salas de aula.

Além disso, por meio de experiências em salas de aula, nota-se o quanto os povos indígenas são invisíveis nos conteúdos escolares. Ao perguntar-se aos alunos se existem indígenas que moram em apartamentos ou que usam tecnologias, logo a resposta será não. Pois os estudantes ainda percebem estes povos como indivíduos que andam nus, pintam a pele e moram em ocas. Este foi mais um motivo que me levou a realizar essa pesquisa.

Assim também, acredita-se que com o desenvolvimento desse trabalho nas escolas, uma movimentação será gerada entre os professores, para valorizar e enfatizar ainda mais a importância desta temática nos currículos escolares.

Escolhemos o município de Maracajá para a realização da pesquisa, por ser o local onde moro. É uma cidade pequena, com apenas três escolas municipais de educação básica, que somam um total de dez professores pedagogos de séries iniciais, das quais, cinco professoras responderam a um questionário aplicado. A escolha das professoras ficou a critério das diretoras escolares, que escolheram algumas das professoras e então, realizaram o convite para a participação na pesquisa.

Assim, a coleta de dados se deu por meio de questionários, procurando compreender como a questão indígena é abordada na sala de aula. Como também, saber o que as professoras conhecem da história e da cultura indígena; o que é ser índio no Brasil hoje e se consideram importante trabalhar esta temática em sala de aula, além de sabermos que metodologias e conteúdos abordam, as dificuldades e os desafios encontrados durante este 


\title{
SABERES PEDAGÓGICOS
}

Revista do Curso de Graduaçāo de Pedagogia - Unesc

ISSN 2526-4559

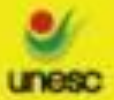

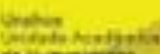

processo; se possuem conhecimento sobre a Lei 11.645/08 e se as professoras têm a Lei como embasamento para trabalhar esta temática em sala de aula.

No referencial teórico, abordamos a aprovação da Lei 11.645/08. Trazendo o seu conteúdo, além da importância de trabalhar esta temática em sala de aula, como também refletimos sobre a importância da formação dos professores para trabalhá-la. Nos apoiamos em ALVES (2015); BORGES (2010); PROPOSTA CURRICULAR NACIONAL (1997, 1998 e 2001); FREITAS (2010); FUNARI E PIÑÓN (2011); SILVA E PORTO (2012); ZUCCHI (2012).

Em seguida, finalizando o presente trabalho, trazemos a metodologia, a apresentação e a análise de dados, além da conclusão e as referências.

\section{LEI 11.645/08: O DIREITO AO ENSINO E AO RECONHECIMENTO DA DIVERSIDADE CULTURAL BRASILEIRA}

A aprovação da Lei 11.645, que aconteceu no dia 10 de março de 2008, alterou a Lei 10.639/03 e além de constar a obrigatoriedade do ensino da história e cultura africana e afro-brasileira incluiu nos currículos escolares a história e a cultura indígena, povos estes, que contribuíram para a formação da sociedade brasileira e espera-se que pela educação sejam reconhecidos, valorizados e respeitados. E que para além de um conteúdo, seja uma temática que possibilite trabalhar com questões ainda não resolvidas no Brasil como o racismo, o preconceito e discriminação e as desigualdades raciais (BRASIL, 2008).

A Lei 11.645/08 determina que

\begin{abstract}
O conteúdo programático a que se refere este artigo incluirá diversos aspectos da história e da cultura que caracterizam a formação da população brasileira, a partir desses dois grupos étnicos, tais como o estudo da história da África e dos africanos, a luta dos negros e dos povos indígenas no Brasil, a cultura negra e indígena brasileira e o negro e o índio na formação da sociedade nacional, resgatando as suas contribuições nas áreas social, econômica e política, pertinentes à história do Brasil (BRASIL, 2008).
\end{abstract}

Ainda de acordo com a Lei, deve ser ensinado aos alunos de maneira interdisciplinar, não em forma de disciplina específica, mas principalmente por meio das aulas de Educação Artística e de Literatura e História do Brasil (BRASIL, 2008). Pois como afirma Saberes Pedagógicos, Criciúma, v. 3, nº3, Edição Especial 2019.- Curso de Pedagogia - UNESC 
Borges (2010. p. 78) “é notória a importância de uma prática interdisciplinar e transversal para a renovação do ensino brasileiro. A exigência de um trabalho interdisciplinar, com a temática História e Cultura Afro-Brasileira e Indígena, vem corroborar com este desejo de inovação."

De acordo com Funari e Piñon (2011), esses assuntos relacionados aos indígenas começaram a fazer parte do currículo escolar entre 1937 e 1943, quando Getúlio Vargas declarou o dia 19 de abril, oficialmente como o Dia do Índio. Assim, esta temática que até então, era ausente no contexto escolar, passa a ganhar visibilidade, passando a ser trabalhada nas escolas, com diversas atividades comemorativas, mas, sem refletir sobre os povos indígenas, sua história e cultura. Permanecendo invisíveis e silenciados durante o resto do ano letivo.

A partir do ano de 1998, esta temática passou a ser enfatizada também nos Parâmetros Curriculares Nacionais de História, num outro contexto de valorização das culturas indígenas. Visto que,

\begin{abstract}
A opção de introduzir estudos de povos indígenas é relevante por terem sido os primeiros habitantes das terras brasileiras e, até hoje, terem conseguido manter formas de relações sociais diferentes das que são predominantes no Brasil. A preocupação em identificar os grupos indígenas que habitam ou habitaram a região próxima do convívio dos alunos é a de possibilitar a compreensão da existência de diferenças entre os próprios grupos indígenas, com especificidades de costumes, línguas diferentes, evitando criar a imagem do índio como povo único e sem história. O conhecimento sobre os costumes e as relações sociais dos povos indígenas possibilita aos alunos dimensionarem, em um tempo longo, as mudanças ocorridas naquele espaço onde vivem e, ao mesmo tempo, conhecerem costumes, relações sociais e de trabalho diferentes do seu cotidiano. (BRASIL, 1998, p. 37).
\end{abstract}

Além dos Parâmetros Curriculares Nacionais de História e Geografia do ano de 1998, trazemos também do ano de 2001, o qual reforça que é fundamental que os alunos possam identificar os grupos indígenas da região, estudando seu modo de vida social, econômico, cultural, político, religioso e artístico. Que identifiquem as semelhanças e as diferenças entre o modo de vida da localidade onde os alunos habitam e o modo de vida da cultura indígena, bem como a ocupação territorial, o relacionamento com a natureza, a construção das moradias, divisão do trabalho, as vestimentas, o lazer, a religiosidade, os mitos de origem, a fabricação de instrumentos de trabalho, os hábitos de higiene, os meios de

Saberes Pedagógicos, Criciúma, v. 3, n³, Edição Especial 2019.-- Curso de Pedagogia - UNESC 


\section{SABERES PEDAGÓGICOS}

Revista do Curso de Graduaçāo de Pedagogia - Unesc

ISSN $2526-4559$
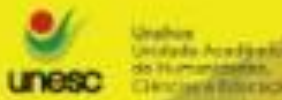

comunicação, os meios de transporte e os diferentes modos de medir o tempo (BRASIL, 2001).

Além disso, este mesmo documento ainda traz que "É fundamental destacar a importância de o professor não realizar comparações que depreciem qualquer cultura, orientando seus alunos também nesse sentido.” (BRASIL, 2001, p. 56).

E em 2008, com a implementação da Lei 11645/08, esta discussão foi ampliada, enfatizando agora a valorização da diversidade cultural de nosso país, trazendo as heranças culturais dos diferentes povos que formaram o Brasil, suas histórias, culturas, lutas e direitos. Devendo ser trabalhadas não apenas em datas comemorativas, mas durante todo o processo de ensino e aprendizagem. Segundo Borges (2010. p. 72), "trata-se de um momento em que a educação brasileira busca valorizar devidamente a história e a cultura de seu povo afrodescendente e indígena, buscando assim reparar danos, que se repetem há cinco séculos, à sua identidade e a seus direitos."

Isto porque, indígenas e afro-brasileiros fazem parte da nossa história e da nossa cultura, contribuindo de diferentes formas para a construção da sociedade brasileira. Funari e Piñón (2011, p. 116) esperam que "os índios passem a ser considerados não apenas um 'outro', a ser observado a distância e com medo, desprezo ou admiração, mas como parte deste nosso maior tesouro: a diversidade."

Alves (2015) aponta que é preciso desmistificar e desconstruir aquela tradicional imagem indígena, onde sua identificação se dava por meio de características físicas, como vestimentas, objetos, costumes, religiões e moradias. Buscando compreender, também, que os índios não são sujeitos apenas do passado, mas também do presente. Que ao longo do tempo, passaram por transformações históricas, mas que isso não interferiu em sua identidade. De acordo com Alves (2015, p. 51), "um índio de calça jeans não perde sua identidade étnica pelo simples fato de apropriar-se da produção material contemporânea."

Como observamos no decorrer deste capítulo, a história e a cultura indígena devem ser incluídas nos currículos escolares e devem também ser trabalhadas durante todo ano letivo. E amparados na Lei 11.645/08, os professores devem acolher suas histórias, sua cultura e lutas e principalmente os valorizá-los e os reconhecê-los como parte integrante da diversidade cultural do nosso país. Bem como contribuindo para desconstruir práticas

Saberes Pedagógicos, Criciúma, v. 3, n³, Edição Especial 2019.- Curso de Pedagogia - UNESC 
discriminadoras e racistas. Freitas (2010. p. 161) afirma que "nossos filhos e alunos têm o direito de saber que as pessoas são diferentes. Que o mundo é plural e a cultura é diversa. Que essa diversidade deve ser reconhecida, respeitada e valorizada." Ademais, os PCN's de História (1998) já destacaram que um de seus objetivos, é que o aluno possa

Conhecer e valorizar a pluralidade do patrimônio sociocultural brasileiro, bem como aspectos socioculturais de outros povos e nações, posicionando-se contra qualquer discriminação baseada em diferenças culturais, de classe social, de crenças, de sexo, de etnia ou outras características individuais e sociais. (BRASIL, 1997, p. 05).

Dessa forma então, notamos a relevância da aplicação da Lei nas escolas, uma vez que possibilita que os estudantes reconheçam a diversidade cultural da nossa sociedade, valorizando a formação da população brasileira e a pluralidade étnica.

Contudo, existe uma grande ausência de profissionais qualificados para trabalhar com esta temática, tornando-se um fator de grande barreira para a concretização da Lei nas escolas. Segundo afirmativa de Zucchi (2012, p. 87),

\footnotetext{
Ao longo dos últimos anos, é possível observar que diversas universidades públicas e privadas vêm oferecendo cursos e promovendo pesquisas sobre o assunto, para atender às demandas dos professores do Ensino Fundamental e Médio. Assim, aos poucos, essas pesquisas são divulgadas, publicadas e colocadas à disposição dos professores dos diferentes níveis de ensino. Portanto, podemos afirmar que as pesquisas históricas sobre as nações indígenas brasileiras são relativamente recentes e ainda insuficientes.
}

Borges (2010) também reforça que é necessário tomar medidas para que as escolas se envolvam nas discussões dessa recente e importante temática, buscando a valorização da diversidade cultural brasileira. De acordo com a autora, "é preciso que os cursos de Licenciatura apresentem disciplinas que discutam a temática História e Cultura Afro-Brasileira e Indígena, oferecendo assim embasamento teórico aos futuros professores." (BORGES, 2010, p. 77).

Com este argumento da autora, podemos perceber que não existe ainda um ensino aprofundado desta temática nos cursos de graduação. Mas é notório que há um grande avanço, pois já existem cursos complementares para professores nesta área. Conforme Silva e Porto (2012, p. 35), “é possível observar um movimento de professores, pesquisadores e autores de 
livros didáticos para superar o desafio de oferecer aos estudantes brasileiros novas possibilidades de interpretação da história dos povos indígenas brasileiros."

Assim, infere-se que está ocorrendo uma lenta, mas gradativa formação de professores relacionado às temáticas indígenas, mas ainda não é suficiente para um completo processo de ensino e aprendizagem. Por isso, o professor deve sempre buscar novas fontes de conhecimentos, inclusive pesquisando livros nas bibliotecas escolares ou artigos na internet, além de se possível conhecer uma comunidade indígena, para que dessa forma esteja seguro dos conhecimentos que possuem.

Para Chiovatto (2000), é esta segurança que dará oportunidades ao educador de gerar diálogos e reflexões sobre o determinado assunto. Contudo, muitos professores não sentem essa segurança, resultado de uma formação precária que dificulta seu papel de mediador, contribuindo para que ao invés de construir conhecimentos com alunos, reproduza conteúdos, no mais das vezes superficiais e estereotipados.

\section{METODOLOGIA, APRESENTAÇÃO E ANÁLISE DE DADOS}

Este trabalho se insere na linha de pesquisa Teoria e Prática Pedagógica. É uma pesquisa de campo descritiva e exploratória, de caráter básico. Segundo Gil

\footnotetext{
As pesquisas descritivas são, juntamente com as exploratórias, as que habitualmente realizam os pesquisadores sociais preocupados com a atuação prática. São também as mais solicitadas por organizações como instituições educacionais, empresas comerciais, partidos políticos etc. (GIL, 1998, p. 42).
}

Sua abordagem é qualitativa, pois buscou-se através desta, o significado e as práticas sobre o ensino da história e da cultura indígena para os professores, não estabelecendo relações quantitativas. Foi realizada na rede municipal de ensino básico de Maracajá, durante o ano letivo de 2018 a partir da aplicação de um questionário com cinco professoras que se dispuseram a participar desta pesquisa, identificadas como P1, P2, P3, P4 e P5. Quanto à formação e tempo de serviço, 


\section{SABERES PEDAGÓGICOS}

Revista do Curso de Graduaçāo de Pedagogia - Unesc

ISSN 2526-4559

\begin{tabular}{|c|c|c|}
\hline Identificação & Formação & $\begin{array}{c}\text { Tempo de Serviço na } \\
\text { área da Educação }\end{array}$ \\
\hline P1 & $\begin{array}{c}\text { Pedagogia } \\
\text { (especialista em ludopedagogia) }\end{array}$ & 16 anos \\
\hline P2 & Pedagogia EAD & 6 anos \\
\hline P3 & Pedagogia & 9 anos \\
\hline P4 & Pedagogia EAD & 3 anos \\
\hline P5 & Pedagogia EAD & 8 anos \\
\hline
\end{tabular}

A partir do questionário aplicado, foram coletados e analisados os seguintes dados:

\subsection{Conhecimento sobre a temática indígena e Lei 11.645/08}

De início em nossa pesquisa, buscou-se saber qual o conhecimento que as professoras questionadas possuem relacionado a esta temática. Questionando-as sobre o que é ser índio no Brasil hoje e se possuem conhecimento sobre a Lei 11.645/08.

De acordo com isso, P2, P3, P4 e P5, dizem que deve ser muito difícil ser índio atualmente no Brasil, pois estão cada vez mais perdendo seus espaços, perdendo o respeito por seus direitos e perdendo também sua identidade cultural. Ainda sobre esta mesma pergunta, P2 ressalta que parte da cultura indígena que ainda é valorizada no Brasil são os artesanatos, dos quais os indígenas produzem para seu cotidiano e os brancos se utilizam disso, considerando uma arte. Diferente destes argumentos, P1 diz

Difícil responder o que é ser índio no Brasil já que fomos ensinados que eles andam nus, pescam e caçam nas florestas. Esta é uma visão romântica sobre o povo alicerce que formou esta nação. Ser índio é ser luta e conquista por direitos retirados, sem perder a particularidade de seu povo. [P1]

Por meio destas respostas, nota-se o quanto as professoras questionadas, com exceção de P1, nos mostram possuir visões estereotipadas sobre o que é ser índio no Brasil

Saberes Pedagógicos, Criciúma, v. 3, n³, Edição Especial 2019.- Curso de Pedagogia - UNESC 


\section{SABERES PEDAGÓGICOS}

Revista do Curso de Graduaçāo de Pedagogia - Unesc

ISSN 2526-4559
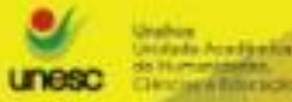

hoje. Oposto aos argumentos das professoras P2, P3, P4 e P5, ser índio hoje no Brasil, para ela não significa perder sua cultura. Todas as pessoas passam por transformações históricas, mas isso não interfere em sua identidade cultural. Alves (2015) já havia dito que os indígenas não perdem sua cultura ao se apropriar de produções materiais contemporâneas. Com isso, percebe-se que a professora P1 foi quem demonstrou possuir mais conhecimentos nesta questão.

Importante frisar que de acordo com a resposta de P2, entende-se que "brancos" citado pela professora esteja relacionado a não indígenas. Funari e Piñón (2011) dizem que os professores costumam apresentar o índio como um contraste com quem seriam os brancos, como se os brancos representassem a população nacional, enquanto os indígenas representassem apenas o outro. "Já está na hora de abandonarmos esse pensamento em função daquele que vê a nossa sociedade, em geral, composta por uma infinidade de grupos étnicos em sua mescla." (FUNARI E PIÑÓN, 2011, p. 10).

Ao serem questionadas sobre a Lei 11.645/08, P2 alega que pouco sabe sobre a Lei, sabe apenas que serve para tornar obrigatório o estudo da cultura indígena, mas não acredita na fidelidade deste ensino, pois são transmitidos pelos brancos. Já P4, diz que a Lei foi criada para falar sobre a cultura indígena. Obteve-se, uma resposta incompleta, pois não contempla o conteúdo da pergunta, sendo que o objetivo era saber se as professoras conhecem os conteúdos presentes na Lei e se sabem qual seu objetivo.

Em contrapartida, P1, P3 e P5 afirmaram que a Lei trata da inclusão da história e da cultura africana, afro-brasileira e indígena na sala de aula, no qual o aluno precisa perceber a influência de diferentes culturas na formação cultural brasileira, formando cidadãos conscientes de pertencer a uma cultura étnica-racial.

Constata-se, a partir das respostas de P1, P3 e P5, que elas estão de acordo com a Legislação Nacional Brasileira, a qual nos traz que a história e a cultura indígena, africana e afro-brasileira, devem ser ministradas em todo o currículo escolar, trabalhando os diversos aspectos da história e da cultura que caracterizam a formação da população brasileira. (BRASIL, 2008).

Quanto às respostas de $\mathrm{P} 2$ e P4, considera-se que não contemplaram a pergunta, pois não responderam qual o conteúdo presente na Lei, citaram apenas que se trata do estudo

Saberes Pedagógicos, Criciúma, v. 3, n³, Edição Especial 2019.- Curso de Pedagogia - UNESC 
da história e da cultura indígena, sendo que este argumento já estava presente no enunciado da pergunta no questionário. P2 ressalta também que não acredita na fidelidade do ensino indígena, pois é transmitido por brancos. Contudo, percebe-se um desvio de pensamento em relação ao conteúdo da pergunta, o que mostra que P2 não possui conhecimento sobre a Lei. Ressalta-se novamente, a expressão "brancos" usada pela professora, que para Funari e Piñón (2011), é uma visão errônea transmitida por muitas escolas, as quais ensinam que não índios são chamados de brancos, sem considerar a diversidade cultural presente em nossa sociedade.

\subsection{Metodologias, uso de livro didático e o dia 19 de abril}

Na sequência, buscamos saber como essa temática é levada para a sala de aula por estas professoras questionadas, procurando saber se elas consideram importante trabalhar este tema nas escolas; quais as metodologias que utilizam; se trabalham o dia 19 de abril, e por fim, se utilizam o livro didático para o desenvolvimento dessas atividades.

Todas as professoras alegam que é importante trabalhar a questão indígena com os alunos. P2 relatou que considera muito importante trabalhar esta temática na escola. P4 relatou apenas que "sim, é muito bom e interessante as crianças saberem e conhecerem um pouco da história dos índios”. As professoras P1, P3 e P5, acreditam que a importância de se trabalhar esta questão se dá pelo fato de conhecer a origem de nossa cultura, pois segundo elas, os indígenas foram pioneiros neste processo.

Como visto no referencial teórico, para se compreender a formação cultural de nosso país, precisa-se conhecer as diversas culturas que fazem parte dela, e os indígenas são parte desta grande diversidade. Freitas (2010) diz que a inclusão deste ensino nas escolas é um direito tanto dos indígenas quanto dos não indígenas, pois todos nós possuímos o direito ao conhecimento da diversidade brasileira. Através do argumento do autor, pode-se perceber que P1, P3 e P5 possuem este conhecimento, enquanto P2 e P4 obtiveram respostas incompletas por não esclarecerem o motivo de considerarem importante este ensino.

Perguntou-se então, quais as metodologias que utilizam para levar este assunto para as salas de aula. Novamente as respostas de P1, P3 e P5 são semelhantes e se completam, ao afirmarem que trabalham a temática indígena ao longo do ano letivo, e não em uma data

Saberes Pedagógicos, Criciúma, v. 3, n³, Edição Especial 2019.- Curso de Pedagogia - UNESC 
específica, sempre fazendo relação da cultura indígena com as demais culturas contribuintes com a formação da sociedade brasileira e buscando novas fontes de conhecimento. Além disso, P3 ainda completa que suas metodologias são voltadas a utilização de leituras, vídeos e fotos relacionados, e são muito trabalhados quando se trata da história do município e do País.

Em contrapartida, P2 diz que dá seguimento ao livro didático, o qual trata esta temática com superficialidade, dando ênfase apenas a arte destes povos. E P4, diz que trabalha suas manias e hábitos, e sua história desde o começo da cultura. Visto isso, entendemos que sua resposta tornou-se de difícil compreensão, pois não se entende o que ela quis dizer com "desde o começo da cultura". O que nos leva a compreender que esta professora possui conhecimentos estereotipados sobre a temática indígena. E sobre a resposta de P2 novamente trazemos Chiovatto (2000) que nos mostra que o professor precisa sempre estar buscando diferentes formas de problematizar o conhecimento trabalhado em sala de aula, para que assim, o aluno construa novos saberes com mais facilidade.

Chiovatto (2000) argumenta que a função do professor quanto mediador é explorar e aprofundar os conteúdos que serão ministrados em sala, objetivando-se assim, a construir um conhecimento significativo para o aluno. Assim sendo, é visível o esforço das professoras P1, P3 e P5, ao buscarem novas ferramentas para aproximar o conteúdo indígena dos estudantes. Contudo, nota-se que P2 age de maneira diferente do argumento da autora, pois não busca formas diferenciadas para gerar significado ao conhecimento para seus alunos, reduzindo seu papel a apenas um transmissor de conhecimentos.

Sobre o dia 19 de abril, perguntou-se as professoras se costumam trabalhar algo relacionado aos indígenas nesta data. P1, P3 e P5 responderam que costumam trabalhar este tema durante todo o ano letivo e não apenas em datas comemorativas, como já haviam citado na questão anterior. P2 consta que trabalha de acordo com o livro didático, então sobre o dia 19 de abril vai depender do conteúdo que o livro trazer. E P4 diz que gosta muito de trabalhar o dia do índio, destaca também que faz muitos trabalhos como pinturas no corpo, cartazes e brincadeiras.

Para Funari e Piñón (2011), a temática indígena deve ser trabalhada no decorrer do ano letivo em diversos aspectos, não apenas no dia 19 de abril. Felizmente pode-se notar que estes aspectos diversos já estão sendo trabalhados em sala, tais como: a compreensão de

Saberes Pedagógicos, Criciúma, v. 3, n³, Edição Especial 2019.- Curso de Pedagogia - UNESC 


\section{SABERES PEDAGÓGICOS}

Revista do Curso de Graduaçāo de Pedagogia - Unesc

ISSN $2526-4559$

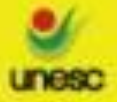

ationians at:

que os povos indígenas já habitavam nosso país antes da chegada dos colonizadores; a valorização do vocabulário, pois muitas palavras são derivadas da cultura indígena; deve ser estudado o índio atualmente, pois fazem parte do presente, mas são geralmente retratados no passado; outro ponto importante para se trabalhar essa temática e que já vem sendo trabalhado é quando diz respeito à população brasileira, no qual diversos grupos étnicos ocupam diferentes espaços territoriais; entre outros aspectos importantes.

Com isso, vimos novamente que $\mathrm{P} 4$, ao trabalhar o dia 19 de abril, não mostra possuir conhecimentos sobre a história e cultura indígena, pois deveria trabalhar ao longo do ano letivo, enfatizando diversos aspectos como estes citados acima. Ademais, ao relatar que faz pinturas corporais nesta data, está dando continuidade aquela imagem tradicional e errônea dos povos indígenas, não possibilitando aos alunos que conheçam as diferentes culturas entre estes povos e ainda, sem perceber que os índios sofreram transformações ao longo do tempo, mas que isso não muda sua identidade, pois eles não deixam de serem índios por não andarem nus, não usarem cocares, arcos e flechas (ALVES, 2015). Como também sua prática se liga à criação do dia do índio como comemoração.

Diferente desta prática, P1, P3 e P5 trabalham os povos indígenas durante o decorrer das aulas, e não apenas em datas comemorativas, mostram que reconhecem o significado e importância deste ensino. E por fim, P2 novamente afirma dar seguimento apenas ao livro didático, e como analisado anteriormente, esta prática, transforma sua função de professora em apenas uma transmissora de informações.

A próxima pergunta do nosso questionário foi relacionada ao livro didático. Buscou-se saber se as professoras adotam o livro didático em suas aulas; quais os conteúdos que este material traz quanto à história e a cultura indígena e se estas mesmas professoras fazem uso de outros recursos além destes livros. No município de Maracajá, é adotado o sistema Positivo de ensino, do qual todas as professoras questionadas fazem uso. Todas afirmaram que usam este material, mas P1, P3 e P5 fazem queixa de que o material não se aprofunda neste tema, trazendo informações sobre os indígenas de uma forma superficial, apenas no período do descobrimento e no período da escravidão. Dessa forma, buscam outras fontes para trabalhar esse assunto como vídeos e fotos. P2 diz que trabalha apenas o que já 
vem determinado nos livros, que não busca outras fontes. E P4 diz que sempre encontra textos e desenhos sobre esse assunto nos livros.

De acordo com Zucchi (2012), "Muitas vezes, costuma-se estudar as nações indígenas do Brasil focando o momento da chegada dos europeus ao território brasileiro e as primeiras décadas da colonização. Depois dessa época, os indígenas "desaparecem" da história do país." Contudo, o autor complementa que isso é um grande erro que precisa urgentemente ser reparado. Os indígenas estavam presentes em nosso país antes mesmo da chegada dos europeus, e permanecem até os dias atuais. Eles nunca sumiram da História do Brasil, só não estão presentes nos livros didáticos.

Assim, percebe-se que P1, P3 e P5 estão de acordo com o autor ao queixar-se dos conteúdos presentes no livro didático, os quais, segundo as professoras questionadas, trazem a história indígena apenas no período do descobrimento e da escravidão.

Em outro momento, relacionado à resposta de P2, vê-se no referencial teórico, que Chiovatto (2000) afirma que o professor mediador não deve apenas transmitir conhecimentos aos alunos,

Isso seria reduzir o professor a um emissor de informações, que não age e nem reage a elas. Se não forem apropriados, retrabalhados constantemente, as informações e os conhecimentos tornam-se vazios, sem significado, transformando-se em dados a serem apenas "captados" e reproduzidos. (CHIOVATTO, 2000, p. 05).

Pode-se constatar, a partir das respostas de P2, que o papel de professor dela é reduzido a um emissor de conhecimentos, como afirmou Chiovatto (2000). Assim, nos parece que esta professora ao referendar o livro didático trata as questões indígenas de forma superficial e estereotipada. Seguinte a isso, nos deparamos com a resposta de P4, que novamente mostra-se incompleta, pois responde que é normal encontrar textos e desenhos sobre o tema, mas não esclarece quais são os conteúdos e nem se ela aborda outras questões além destas presentes no livro, 


\subsection{Dificuldades, desafios e formação de professores}

Para finalizar a pesquisa, questionamos as professoras sobre as dificuldades e os desafios que encontram para a concretização da Lei no âmbito escolar, buscando saber também se são oferecidos a essas educadoras, cursos de formação de acordo com este tema.

Todas afirmaram que não possuem curso de formação nesta área, P3 acrescenta que quando trabalha este conteúdo precisa buscar leituras a respeito disso para aprofundar seus conhecimentos. Em relação às dificuldades e os desafios, as respostas foram semelhantes às anteriores, pois as professoras relatam que a dificuldade encontrada é a falta de conhecimento a respeito do tema, no qual precisam pesquisar em outras fontes. Com exceção de P4, única professora que relatou não possuir nenhuma dificuldade para trabalhar este conteúdo em sala.

De acordo com Borges (2010), esta temática é recente em nossa sociedade. E uma das medidas a ser tomada é a inclusão de disciplinas que discutam o ensino da história e da cultura indígena nos cursos de Licenciatura, pois dessa forma, os futuros professores terão embasamento teórico para levar este assunto para a sala de aula.

Zucchi (2012, p. 87) também ressalta que, "podemos afirmar que as pesquisas históricas sobre as nações indígenas brasileiras são relativamente recentes e ainda insuficientes." Com este argumento e ainda com argumentos de outros autores durante nosso referencial teórico, compreende-se a queixa das professoras sobre a falta de conhecimento e a falta de formação neste ramo.

Além disso, destaca-se a resposta de $\mathrm{P} 3$, ao constar que mesmo não possuindo formações na área e com pouco conhecimento, busca sempre novos saberes sobre este assunto em outras fontes para se trabalhar em sala. Nota-se sua atitude no referencial teórico deste artigo, quando Silva e Porto (2012) alegam perceber um movimento de professores para tentar oferecer aos estudantes, novas possibilidades de concepção da história dos povos indígenas.

Contudo, durante a coleta de dados para a produção deste artigo, foi realizada uma pesquisa nas bibliotecas das escolas onde as professoras trabalham. Nessas bibliotecas, existem livros que são direcionados aos professores, que falam sobre o ensino da disciplina de história, e nestes mesmos livros, há capítulos exclusivos sobre o ensino da temática indígena.

Saberes Pedagógicos, Criciúma, v. 3, n³, Edição Especial 2019.- Curso de Pedagogia - UNESC 


\section{SABERES PEDAGÓGICOS}

Revista do Curso de Graduaçāo de Pedagogia - Unesc

ISSN 2526-4559

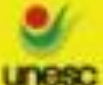

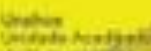

Porém, nenhuma das professoras falaram sobre esses livros em suas respostas, o que nos leva a entender que falta um pouco de esforço da parte delas, em buscar novas fontes de conhecimentos sobre este assunto, pois não pesquisam nem mesmo nos materiais presentes na biblioteca escolar do local onde trabalham.

\section{CONCLUSÃO}

Por meio da realização desta pesquisa de campo, viu-se o quanto o ensino da temática indígena nas escolas ainda é desconhecido. Percebeu-se também, como a visão de algumas das professoras sobre os povos indígenas é estereotipada. É certo que não são ofertados cursos de formação nesta área, mas é notável o descaso das professoras em pesquisar e conhecer mais sobre estes povos. Então, pergunta-se: como ensinar sobre algo que não se conhece?

Constata-se, por meio das respostas das professoras, que o ensino acontece daquela tradicional e errônea forma sobre o qual a imagem indígena é reforçada como o outro, como o não branco, que andam nus e usam cocares, reforçada como data comemorativa a cada 19 de abril. Onde os alunos percebem que para ser índio é necessário andar nu, usar cocar, caso contrário, perdem suas culturas e uma suposta identidade.

Ademais, relacionado ao término da pesquisa, vimos que nossos objetivos foram atingidos, pois conseguimos constatar como vem acontecendo o ensino da história e da cultura indígena nas escolas da rede municipal de Maracajá, bem como foi visto se as professoras recebem formação nesta área e se são suficientes para a aquisição de conhecimentos sobre este tema, quais os conhecimentos que possuem sobre a Lei 11645/08, quais as dificuldades e os desafios que encontram para levar o ensino desta temática para as escolas.

Porém, mesmo que os objetivos da pesquisa tenham sido atingidos, os resultados não foram satisfatórios, pois as respostas de algumas professoras não estão em concordância com os autores citados no referencial teórico, entendemos o quanto a formação de professores neste ramo é precária, não dando total suporte as professoras para que trabalhem adequadamente estes assuntos em sala de aula. Constata-se que este é um grande fator para

Saberes Pedagógicos, Criciúma, v. 3, n³, Edição Especial 2019.- Curso de Pedagogia - UNESC 


\section{SABERES PEDAGÓGICOS}

Revista do Curso de Graduaçāo de Pedagogia - Unesc

ISSN $2526-4559$

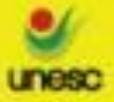

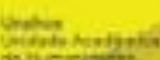
at:

que permaneçam estas visões estereotipadas que as professoras pesquisadas possuem. Mas nota-se também, um descaso por parte das professoras em buscar conhecimentos em outras fontes, como em internet ou até mesmo, na biblioteca da escola em que trabalham. Espera-se que, com a realização da pesquisa, inquietações sejam levantadas nas escolas participantes, e que assim, atitudes sejam tomadas para a correção e melhoria deste ensino.

Contudo, os professores e os alunos precisam perceber que os índios não existiram apenas no período do descobrimento do Brasil ou que serviram como escravos para os colonizadores. Os índios são e vivem muito além disso, e nossos alunos precisam perceber e conhecê-los, ontem e hoje. E se a história indígena acontece desde antes do descobrimento do Brasil até a atualidade, por que então não trabalhar esses povos durante o decorrer do ano letivo, e assim esquecer o dia 19 de abril como data comemorativa presa ao passado?

Dessa forma, fica o convite para as professoras das séries iniciais: Porque não pesquisar sobre as comunidades indígenas em Santa Catarina, como os Kaigang, os Guaranis e os Xokleng? Seria importante trabalhar a luta desses povos para conquistar direitos às suas próprias terras. Conhecer mais sobre os modos de vida indígenas que são tão diferentes do nosso e muito mais respeitosos com a natureza. Trabalhar sobre seus mitos, suas crenças, seus costumes, suas lutas e formas de vida. Assim, as professoras estarão aproximando seus alunos das culturas indígenas também presentes em Santa Catarina, reconhecendo o valor destes povos, sua história e cultura para a formação cultural de nossa sociedade.

\section{REFERÊNCIAS:}

ALVES, Adriana de Carvalho. Ensino de História e Cultura Indígena: trabalhando com conceitos, desconstruindo estereótipos. Revista Espaço Acadêmico, Maringá, v. 14, n. 168, p.42-53, maio 2015. Mensal.

BORGES, Elisabeth Maria de Fátima. A Inclusão da História e da Cultura Afro-brasileira e Indígena nos Currículos da Educação Básica. Mestrado História, Vassouras, v. 12, n. 1, p.71-84, jan./jun., 2010.

BRASIL. Lei no 11645/08, de 10 de março de 2008. . Brasília, 10 mar. 2008. Disponível em: <goo.gl/WEzIV2>. Acesso em: 29 mar. 2018. 


\section{SABERES PEDAGÓGICOS}

Revista do Curso de Graduaçāo de Pedagogia - Unesc

ISSN 2526-4559
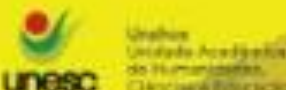

ionim

BRASIL. Parâmetros Curriculares Nacionais (PCNs). História e Geografia. Ensino Fundamental. Brasília: MEC/SEF, 1997.

BRASIL. Parâmetros Curriculares Nacionais (PCNs). História e Geografia. Ensino Fundamental. Brasília: MEC/SEF, 1998.

BRASIL. Parâmetros Curriculares Nacionais (PCNs). História e Geografia. Ensino Fundamental. Brasília: MEC/SEF, 2001.

CHIOVATTO, Milene. O professor mediador. Museu para todos. Disponível em: http://museu.pinacoteca.org.br/wpcontent/uploads/sites/2/2017/01/MILA_CHIOVATTO_o_professor_mediador.pdf Acesso em: $15 / 05 / 2018$

FREITAS, Itamar. A experiência indígena no ensino de História. In: OLIVEIRA, Margarida Maria dias de. (Org.). História. Brasília: Ministério de Educação, Secretaria de Educação Básica, 2010. p. 159-192.

FUNARI, Pedro Paulo; PIÑÓN, Ana. A temática indígena na escola: subsídios para os professores. São Paulo: Contexto, 2011. 124 p.

GALLOIS, Dominique Tilkin. Patrimônio Cultural Imaterial e Povos Indígenas Exemplos no Amapá e norte do Pará. São Paulo: Iépe, 2006.

GIL, Antonio Carlos. Como elaborar projetos de pesquisa. São Paulo: Atlas, 1988. 176 p.

SILVA, Marco; PORTO, Amélia. Nas trilhas do ensino de história: Teoria e Prática. Belo Horizonte: Rona, 2012. 128 p.

ZUCCHI, Bianca. O ensino de história nos anos iniciais do Ensino Fundamental: teoria, conceitos e uso de fontes. São Paulo: Somos Mestres, 2012. 160 p.

Recebido: 12/06/2019

Aprovado: 01/08/2019

Publicado: 20/09/2019 